IdeAs

Idées d'Amériques

$10 \mid 2017$

États-Unis / Cuba : une nouvelle donne?

\title{
Crisis histórica, gobernabilidad y reforma económica: hacia una nueva fase del extractivismo en Venezuela
}

Emiliano Teran Mantovani

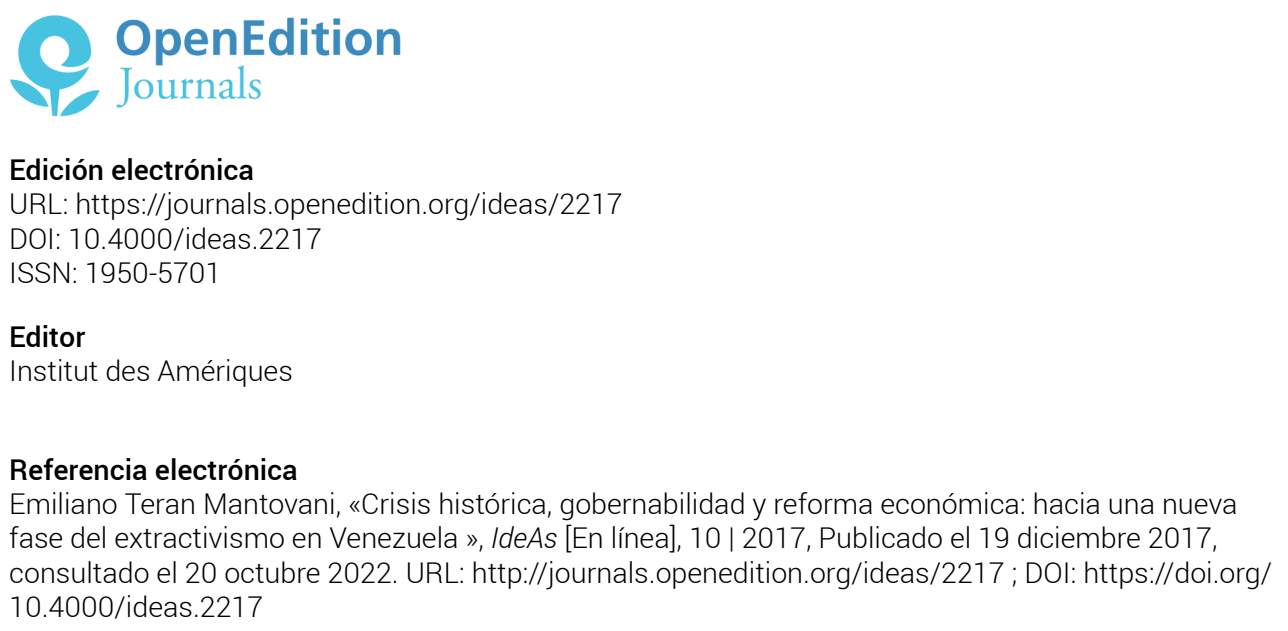

Este documento fue generado automáticamente el 20 octubre 2022.

\section{(c) $(1) \Theta \Theta$}

Creative Commons - Atribución-NoComercial-SinDerivadas 4.0 Internacional - CC BY-NC-ND 4.0 https://creativecommons.org/licenses/by-nc-nd/4.0/ 


\title{
Crisis histórica, gobernabilidad y reforma económica: hacia una nueva fase del extractivismo en Venezuela
}

\author{
Emiliano Teran Mantovani
}

\section{La encrucijada del proceso bolivariano venezolano}

1 El proceso bolivariano se encuentra en una encrucijada. La crisis que se vive en la actualidad no tiene precedentes en la historia del país. La economía vive una especie de desquiciamiento generalizado que se desbordó principalmente desde el derrumbe de los precios del crudo en 2014, siendo que las instituciones formales se encuentran socavadas, la corrupción ha hecho metástasis y las economías informales (en buena medida articuladas con grupos delincuenciales) adquieren un extraordinario auge. El PIB viene en caída sostenida desde $2014(-3,9 \%,-5,7 \%$ en 2015 , y dramáticos descensos que, ante la carencia de datos oficiales en el país, han sido estimados por el FMI en -16,5\% para 2016 y -12\% para 2017) (FMI, 2017); una inflación galopante que supera los 100 puntos en 2015 , escala a $254 \%$ en 2016 y se estima en $657 \%$ para 2017 ; una acelerada depreciación real de la moneda y un alto componente especulativo en el mercado negro de divisas; caída de la producción agrícola, industrial (Díaz A., 2017; Meza J.G., 2017) e inclusive petrolera -2.571 .000 barriles de crudo diario para 2016- (PDVSA, 2017), lo que a la vez se vincula con una notable escasez de bienes de consumo, alimentos y medicinas; descenso sostenido de las reservas internacionales -10.035 millones US $\$$ en junio de 2017 (BCV, 2017), su monto más bajo en 21 años-; y una deuda externa bruta que, según Cepal, alcanza los 132 mil millones US\$ en 2016 (CEPAL, 2017).

2 Todo esto se ha desarrollado en el contexto de la ausencia física del presidente Hugo Chávez (2013), que ha generado una crisis hegemónica y fragmentado el mapa de actores y los campos en disputa. El conflicto político se ha hecho cada vez más intenso 
hasta tomar un cariz bélico extremadamente peligroso, donde el contrato social ha sido desbordado y los marcos democráticos notoriamente vulnerados por los actores en pugna. Venezuela ha estado en el ojo del huracán geopolítico, y la agresiva política exterior que impulsa el Gobierno de los Estados Unidos en su contra ha tenido un importante rol en este proceso, destacando la reciente imposición de sanciones financieras al país, que prohíben negociaciones sobre nuevas emisiones de deuda y bonos por parte del Gobierno venezolano, entre otras restricciones (Trump D., 2017).

situación no es sólo el resultado de una escalada súbita de factores críticos, o bien se detona únicamente por el estallido de un conflicto político reciente o por factores exógenos de intervención, sino que también es el desenlace de un punto de bifurcación en el cual, en el proyecto bolivariano se optó por la profundización del extractivismo y, por tanto, se reforzaron los anclajes históricos con la enorme dependencia que genera, y los terribles impactos económicos, sociales y ambientales que produce.

4 Este punto de bifurcación se configuró en el período de hegemonía y radicalización del proyecto chavista (2004-2009), el cual se abre luego de la muy conflictiva, inestable y «reformista» primera etapa (1999-2004). En este, se van a desarrollar las condiciones más favorables para una agenda popular y revolucionaria que tal vez se hayan tenido nunca en toda la historia contemporánea de Venezuela, al calor además del boom de las materias primas.

El surgimiento y despliegue del Socialismo del Siglo XXI -que posteriormente iba también a ser nombrado como «eco-socialismo»- como programa fundamental del Gobierno Bolivariano, se va a producir en consonancia con la primera oleada de reestructuración económica del proceso revolucionario (de perfil desarrollista/ modernizador), en la cual prácticamente todos los proyectos y emprendimientos económicos de gran escala son revisados, reformulados, relanzados y en su gran parte estatizados. Se trata de un re-impulso del extractivismo a escala nacional, con la Faja Petrolífera del Orinoco como gran bastión, la reorganización y promoción de polos de desarrollo, proyectos de infraestructura energética y conexión con los planes regionales IIRSA -con apoyo de Brasil-, el surgimiento en 2011 del entonces y todavía no tan controvertido «Arco Minero de Guayana», y la misión de convertir a Venezuela en una «Potencia Energética Mundial» que, entre otras cosas, extraerá 6 millones de barriles de crudo diario para el año 2021. La sistematización de toda esta geoarquitectura extractivista era finalmente sintetizada y presentada de manera detallada y codificada en 2012, con el «Plan de la Patria» 2013-2019.

6 Aquí es donde se consolida eso que en el debate latinoamericano reciente se ha llamado el «neo-extractivismo progresista» (Gudynas E., 2009; Svampa M. 2013; Acosta A. 2011), el cual mantiene este patrón económico de extracción masiva de materias primas para la exportación, ahora con un Estado que se hace más activo, que capta mayores rentas y genera una repartición de las mismas dirigidas a programas sociales, lo que le otorga mayor legitimidad social. Esta lógica rentista de alto impacto social y ambiental, magnificada por un nuevo fenómeno de «enfermedad holandesa» y perturbada por la crisis económica mundial (2008-2009), acentuó los factores estructurales de agotamiento del capitalismo rentístico venezolano -la larga crisis 1983-2017- (Baptista A., 2010; Teran Mantovani E., 2014) y marca determinantemente el rumbo actual de la Revolución Bolivariana. 


\section{Hacia una nueva fase del extractivismo en Venezuela}

7 Luego de un período de estancamiento del proceso bolivariano (2009-2013), nos encontramos en esta etapa que podemos denominarla de caotización económica y beligerancia política (2013-2017). Los factores descritos han configurado las condiciones para un significativo giro del régimen político y económico dominante desde los inicios de la Revolución Bolivariana: nacionalismo energético, democracia participativa y protagónica, economía anti-neoliberal en favor de los más desfavorecidos y soberanía nacional. Esto se ha traducido, al menos desde 2014, en una reorganización de la composición del conjunto de actores hegemónicos; de los marcos de negocios y organización geo-económica del territorio -resaltando la Agenda Económica Bolivariana y sus 15 «Motores Productivos»-; y de los esquemas de gobernabilidad, todo lo cual parece encuadrado en la «plenipotenciaria» Asamblea Nacional Constituyente, instalada formalmente el 4 de agosto de 2017.

8 A partir del conjunto de políticas que han sido propuestas y ejecutadas en este período, es posible adelantar algunos rasgos generales de este giro del extractivismo en el país:

a. El impulso de políticas de flexibilización económica y un «régimen especial de inversiones» (como lo ha llamado el ministro de petróleo, Eulogio del Pino) (AVN, 2017), como se evidencia, por ejemplo, con la aparición de figuras de participación mayoritariamente privadas en casos particulares contemplados para actividades petroquímicas, como lo explicita la reforma de la Ley Orgánica para el Desarrollo de las Actividades Petroquímicas (Decreto $\mathrm{N}^{\circ}$ 2.171, Gaceta No. 6.210 Extraordinario, 30/12/2015); o bien formas de flexibilización en las propias políticas de territorialización, como la creación de las Zonas Económicas Especiales o Zonas de Desarrollo Estratégico Nacional (Ley de Regionalización Integral para el Desarrollo Socioproductivo de la Patria, Decreto $\mathrm{N}^{\circ} 1.425$, No. 6.151 Extraordinario, 18/11/2014), que implican una liberalización radical de territorios para un «desarrollo» acelerado de los mismos.

b. Ampliación planificada de las fronteras y cuotas de la extracción a escala nacional, donde resalta el relanzamiento del mega-proyecto «Arco Minero del Orinoco» (AMO), una amplia zona de $111846 \mathrm{kms}^{2}$ (12\% del territorio nacional) ubicada en los estados sureños de Bolívar y Amazonas, con áreas ricas en oro, coltán, diamantes, hierro, bauxita, entre otras, que a la vez se solapan con delicadas zonas de reserva naturales y territorios indígenas. Se han anunciado negociaciones con unas 150 empresas internacionales, planteándose una nueva importancia histórica para la minería en el país. En la actualidad se ha concretado la conformación de empresas mixtas como «Siembra Minera» (proyecto «Las Brisas», oro) o «Parguaza» y «Oro Azul» para la extracción de coltán. También resaltan los proyectos de inversiones foráneas para el incremento de la «producción» en la Faja Petrolífera del Orinoco, lo que en conjunto con el AMO evidencia que estamos ante la configuración de un nuevo núcleo geográfico de extracción en la cuenca del río Orinoco, que progresivamente podría suplantar en importancia a las tradicionales cuencas petroleras de la zona norte del país. Por último, destacan la búsqueda de reconexión de pozos en el occidente del país; relanzamiento de los grandes proyectos gasíferos offshore, con el proyecto Cardón IV en la península de Paraguaná como punta de lanza; re-impulso y reactivación de las obras del Puerto de Aguas Profundas de la península de Araya; la reactivación de minas que cayeron en el reciente período de crisis como Loma de Níquel y Carbozulia, junto a proyectos más pequeños de minería no metálica en varias partes del país; así como la creación de la Faja Pesquera en la fachada Caribe-Atlántica; entre otras.

c. Vinculación del relanzamiento del extractivismo con el endeudamiento público externo a través de mecanismos de financiarización masiva de los «recursos naturales», tales como la 
certificación de reservas (Proyecto Magna Reserva Minera), o el pago de deuda con commodities, como fuese propuesto por el ministro Del Pino para levantar la "producción» de Carbozulia, ofreciendo el carbón de «alta calidad» como retribución a las transnacionales.

d. Alianza directa y formal entre el sector militar y corporaciones transnacionales para la gestión de emprendimientos extractivos, como ocurre con la conformación de la empresa militar Camimpeg (Compañía Anónima Militar de Industrias Mineras, Petrolíferas y de Gas, Decreto No. 2.231. Gaceta No. 40.845, 10/02/2016) y su asociación en empresas mixtas en el Arco Minero del Orinoco.

e. Configuración de los marcos de un estado de excepción permanente, el cual se ha materializado a través de decretos desde enero de 2016, declarando el «estado de excepción y emergencia económica en todo el territorio nacional», y siendo prorrogados continuamente. En el Decreto $N^{\circ} 2.849$ del 13 de mayo de 2017 se indica que podrán ser restringidas las garantías para el ejercicio de los derechos consagrados en la Constitución, con algunas salvedades.

f. En este marco de «situación extraordinaria», de intenso conflicto político en el país y de las sanciones económicas impuestas a Venezuela por el Gobierno de los Estados Unidos de Norteamérica, se impulsa una creciente militarización de todos los ámbitos de la vida, junto a mecanismos de intervención policial directa en barrios urbanos y rurales, y zonas de minería ilegal (como la llamada «Operación de Liberación del Pueblo» - OLP) y la securitización militar de las áreas de «recursos naturales estratégicos».

9 Este es el marco político que se está configurando en este período post-2013 en Venezuela, el cual, como se evidencia, reformula los términos y la intensidad de los procesos de apropiación y capitalización de la naturaleza y de los esquemas de gobernabilidad. Nos encontramos ante la segunda oleada de reestructuración económica de la Revolución Bolivariana, pero esta vez en el contexto de un nuevo escenario histórico de acumulación por desposesión en el país y un proceso de (re)colonización de las nuevas fronteras de las commodities, lo que en concreto está representando un asalto final a los pueblos indígenas y las últimas áreas protegidas del país, así como un socavamiento de los medios de vida de todos los venezolanos.

La alianza fundamental de poder planteada entre el sector militar y las corporaciones transnacionales, traza las rutas más estables y predecibles del rumbo económico a partir del mapeo de los «recursos naturales», al tiempo que parece conformar un esquema de gobernabilidad que garantice la viabilidad de los cambios económicos en curso, lo que hace que las formas más democráticas que caracterizaron previamente a la Revolución Bolivariana se vayan poniendo en suspenso, mientras los entramados socio-territoriales son permeados por las lógicas de militarización y securitización.

11 En el contexto de lo antes expuesto y del agotamiento del período progresista en América Latina (Modonesi M., 2015; Peters S., 2016; Svampa M., 2016), conviene resaltar que los rasgos del 'neo-extractivismo progresista' que han diferenciado a estos regímenes respecto a sus pares más conservadores, se van desvirtuando considerablemente y perdiendo vigencia, ante los cambios en curso. Parece que le decimos adiós a este régimen y sostenemos que estamos ante una nueva fase del extractivismo en Venezuela que con el transcurso del tiempo será necesario definir y caracterizar con mayor detalle.

12 El nacimiento de la Asamblea Nacional Constituyente (ANC) abre un período que se inaugura con una victoria política del Gobierno nacional, presidido por Nicolás Maduro. El escenario de confrontación, estado de excepción y el perfil despótico que se configura como régimen de gobierno, le otorga a la ANC un potencial de 
reordenamiento autoritario-militar-corporativo de la sociedad y de formalización de esta nueva política económica que se viene ensamblando. El objetivo sería derribar obstáculos significativos al capital o cercenar formas de contraloría política y la división de poderes; hacer prevalecer sobre todo los intereses de «Seguridad Nacional» y la razón de Estado; y generar marcos para la securitización y «pacificación» de la sociedad.

13 Ante esta situación y la debacle de la Mesa de la Unidad Democrática (MUD), parece que el principal actor que podría confrontar y detener estas tendencias tan regresivas son los segmentos más críticos, movilizados y politizados de las propias bases populares del chavismo. Esto, unido a un conjunto de organizaciones «outsiders» de la polarización que se encuentran atomizadas en todo el país, podría generar condiciones para el surgimiento de una masa crítica que haga resistencia a este desmontaje de los componentes progresistas del proceso bolivariano. El panorama no es alentador pero la volatilidad de la situación del país y sus altos niveles de incertidumbre otorgan mayores espacios a factores desencadenantes y nuevos escenarios.

\section{BIBLIOGRAFÍA}

Acosta, Alberto, Extractivismo y neoextractivismo: dos caras de la misma maldición, México, Ediciones Abya Yala y Fundación Rosa Luxemburgo, Más allá del desarrollo, 2011, p. 83-118.

AVN, «Proponen para la Faja Petrolífera del Orinoco régimen especial de inversiones», 25 de enero de 2017, http://www.avn.info.ve/contenido/proponen-para-faja-petrol\%C3\%ADfera-delorinoco-r\%C3\%A9gimen-especial-inversiones, página consultada 23 de octubre de 2017.

Baptista, Asdrúbal, Teoría económica del capitalismo rentístico, Caracas, Banco Central de Venezuela, 2010 .

BCV, «Indicadores», Banco Central de Venezuela, 2017, http://www.bcv.org.ve/cuadros/2/231.asp? $\mathrm{id}=32$, página consultada 22 de octubre de 2017.

CEPAL, «Estudio Económico de América Latina y el Caribe a 2017», 2017, http:// repositorio.cepal.org/bitstream/handle/11362/42001/4/EEE2017_Venezuela_es.pdf, página consultada 22 de octubre de 2017.

Díaz, Ana, «90\% de los industriales afirma que su producción cayó a finales de 2016», El Nacional, 29 de marzo de 2017, http://www.el-nacional.com/noticias/economia/los-industriales-afirmaque-produccion-cayo-finales-2016_87807, página consultada 22 de octubre de 2017.

FMI, «Perspectivas de la economía mundial», octubre 2017, https://www.imf.org/es/ Publications/WEO/Issues/2017/09/19/world-economic-outlook-october-2017, página consultada 22 de octubre de 2017.

Gudynas, Eduardo, «Diez tesis urgentes sobre el nuevo extractivismo» in Jürgen Schludt et al., Extractivismo, política y sociedad, ,Quito, CAAP/Claes, 2009, p. 187-225. 
Meza, José Gregorio, «Fedeagro: 2017 será un año de caída de la producción agrícola», El Nacional, 8 de mayo de 2017, http://www.el-nacional.com/noticias/economia/fedeagro-2017-sera-anocaida-produccion-agricola_181094, página consultada 22 de octubre de 2017.

Modonesi, Massimo. «Fin de la hegemonía progresista y giro regresivo en América Latina. Una contribución gramsciana al debate sobre el fin de ciclo», Viento Sur, n¹42, Madrid, octubre 2015, p. 28.

PDVSA, «Informe de gestión anual 2016», 2017, http://www.pdvsa.com/images/pdf/iga/ IGA_2016_Compilado.pdf, página consultada 22 de octubre de 2017.

Peters, Stefan, «Fin del ciclo: el neo-extractivismo en Suramérica frente a la caída de los precios de las materias primas. Un análisis desde una perspectiva de la teoría rentista» in Hans-Jürgen Burchardt, et al. (eds.), Nada dura para siempre. Neo-extractivismo tras el boom de las materias primas, Quito, Universidad Andina Simón Bolívar, 2016, p. 21-54.

Svampa, Maristella, «Consenso de los Commodities y lenguajes de valoración en América Latina». Nueva sociedad, n²44, 2013, p. 30-46.

Svampa, Maristella. «América Latina: Fin de ciclo y populismos de alta intensidad» in Autores varios, Rescatar la esperanza. Más allá del neoliberalismo y el progresismo, Entrepueblos, 2016, p. $62-113$

Teran Mantovani, Emiliano. «La crisis del capitalismo rentístico y el neoliberalismo mutante (1983-2013)», Fundación Celarg, Caracas, 2014.

Trump, Donald, «Imposing Sanctions with Respect to the Situation in Venezuela», the White House, 25 de agosto 2017, https://www.whitehouse.gov/the-press-office/2017/08/25/ presidential-executive-order-imposing-sanctions-respect-situation, página consultada $22 \mathrm{de}$ octubre de 2017.

\section{AUTOR}

\section{EMILIANO TERAN MANTOVAN}

Sociólogo de la Universidad Central de Venezuela, mención «Magna Cum Laude» y Master en Economía Ecológica por la Universidad Autónoma de Barcelona. Es investigador en ciencias sociales orientado a temas sobre ecología política, extractivismo, movimientos sociales y alternativas al desarrollo. Correo electrónico: fighters1985@gmail.com 